\title{
KENDALI PUTARAN MOTOR ASINKRON 3 PHASA DENGAN VSD TIPE ATV312HU15N4
}

\author{
M. Suyanto ${ }^{1)}$, Subandi' ${ }^{2}$, Syafriudin ${ }^{3)}$, Arif Maulana Fikri ${ }^{4)}$ \\ 1,2,3,4) Jurusan Teknik Elektro, Institut Sains \& Teknologi AKPRIND Yogyakarta \\ Jl.Kalisahak No 28 Komplek Balapan Jogjakarta \\ Telepon: (0274) 563029, Fax. (0274)563847 \\ E-mail: myanto@akprind.ac.id ${ }^{1)}$, suba@akprind.ac.id ${ }^{2)}$, arifmafi@gmail.com ${ }^{3)}$
}

\begin{abstract}
Abstrak
Pada perkembangan industri saat ini, penggunaan motor asinkron 3 phasa sering dimanfaatkan, sebagai penggerak perangkat kendali dengan putaran penuh atau relatif tetap. Pengaturan putaran dari motor asinkron, sangat berpengaruhi pada nilai frekuensi terhadap tegangan yang inputkan kedalam motor. Penelitian ini membahas masalah kendali putaran motor asinkron 3 phasa menggunakan variable speed drive (VSD) tipe ATV312HU15N4, frekuensi $50 \mathrm{~Hz}, 2 \mathrm{HP}$. Cara tepat penggunaan energi listrik, untuk operasional motor asinkron 3 phasa adalah menggunakan VSD. VSD merupakan suatu alat berupa rectifier, inverter dan kontroler. Sedangkan pengaturan frekuensi bertujuan untuk mengatur kendali putaran motor asinkron tiga phasa arus bolak balik. Berdasarkan hasil pengujian di labolatorium diperoleh bahwa kendali kecepatan motor menggunakan VSD, mempunyai arus starting rendah berkisar (5,91-7,76A). Sedangkan kondisi berbeban kecepatan putar berkisar (313-1509rpm). Kondisi ini dapat disesuaikan dengan perubahan frekuensi, walaupun beban bertambah atau berkurang.
\end{abstract}

Kata kunci: VSD, motor asinkron, Inverter

\begin{abstract}
In the current industrial development, the use of 3 phase asynkron motors is widely used as a drive of equipment at full or relatively constant speed. The rotation arrangement of the asynkron motor is greatly influenced by the value of the frequency of the AC voltage entering the motor. This study discusses the problem of speed control of three phase induction motors using variable speed drive (VSD) type ATV312HU15N4, frequency $50 \mathrm{~Hz}, 2 \mathrm{HP}$. The right way to use electrical energy, for 3 phase asynchronous motor operations is to use VSD. VSD is a device consisting of a rectifier, inverter and controller. While the frequency setting aims to regulate the speed control of the 3 phase asynkron motor alternating current. Based on the results of testing in the laboratory found that the motor speed control using VSD, has a low starting current range (5.91-7.76A). While the load conditions and rotational speed range (313-1509rpm). This condition can be adjusted with changes in frequency, even if the load increases or decreases.
\end{abstract}

Kywords: VSD, asynkron motors, Inverter

\section{PENDAhuluan}

Perkembangan ilmu pengetahuan dan teknologi didunia industri, banyak memanfaatkan peralatan listrik sebagai kontrol putaran motor asinkron 3 phasa. Peralatan pada industri kebanyakan, catu dayanya menggunakan energi listrik bolak-balik yang handal dan mempunyai efisiensi tinggi.

Adapun aplikasi yang sering dimanfaatkan di industri adalah motor asinkron 3 phasa. Agar dapat berputar dengan baik, maka diperlukan catu daya disesuaikan jenis dan tipe motornya. Sedangkan Motor arus searah, diperlukan catu daya tegangan searah (DC).

Untuk memutar dan mengendalikan motor asinkron 3 phasa diperlukan, suatu rangkaian kendali putaran pada poros motor asinkron. Motor listrik membutuhkan suplai tegangan, sesuai dengan kebutuhannya untuk kecepatan putar poros dan torsinya. Pengendalian putaran motor pada industri, secara konvensional kurang menguntungkan. Hal ini banyak menimbulkan rugi daya cukup besar, sehingga diperlukan pengendalian kecepatan putar poros yang lebih baik.

Ada cara ekonomis dengan menerapkan modul perangkat elektronika, atau memanfaatkan rangkaian elektronika daya (Power Electronics), yaitu dengan menerapkan rangkaian perangkat elektronika. Seperti mengendalikan perangkat kelistrikkan yang berdaya besar 
seperti, motor asinkron 3 phasa. Dengan kemajuan Power Electronics ternyata banyak memberikan solusi, terhadap perkembangan pada industri maju untuk dapat melakukan pengendalian peralatan-peralatan yang memanfaatkan rangkaian elektronik. Karena rangkain elektronik, dapat bekerja dengan arus dan tegangan secara efektif dan efisien.

Perubahan konversi besaran listrik ke mekanis, dengan cara konvensional dianggap tidak ekonomis, sekarang mulai bergeser dengan penggunaan peralatan elektronik digital, yang menerapkan sistem pengendalian switching elektronik. Sehingga proses diera digital dalam bidang industri sekarang, banyak digunakan peralatan pengendali dengan Variable Speed Drive (VSD).

Perangkat VSD ini, banyak dimanfaatkan sebagai peralatan pengendalian putar motor asinkron 3 phasa. Tegangan arus bolak-balik banyak dimanfaatkan, sebagai catu daya pada motor induksi asinkron. Perangkat VSD pada prinsipnya terdapat, beberapa rangkaian komponen elektronik didalamnya seperti rectifier, inverter, dan microcontroller.

Penggunaan VSD cukup banyak, sebagai alat pengendalian putaran motor asinkron arus bolak balik, membuat penulis tertarik dengan judul yang berkaitan tentang "Kendali Putaran Motor Asinkron 3 Phasa dengan VSD Tipe ATV312HU15N4".

\subsection{Tinjauan Pustaka}

Penelitian ini telah banyak dilakukan dan dituliskan dalam beberapa jurnal antara lain: Masalah pengaruh beban tak seimbang dengan harmonisa VSD motor asinkron 3 phasa.

Hasil penelitian tersebut menunjukkan, bahwa pada pengendalian kecepatan motor asinkron penggerak mesin extruder, menggunakan inverter, energi yang dibutuhkan lebih kecil energinya $65,61 \mathrm{kWh}$. Dalam pengoperasian $6 \mathrm{jam} /$ hari karena kebutuhan kecepatan, hanya 500-600 rpm.[1].

Menurut (Atmam, dkk. 2018), tentang "Pengujian unjuk kerja VSD dengan beban motor induksi", memaparkan bahwa kecepatan motor dapat diubah dengan cara mengubahubah frekuensi pada VSD. Hasil pengujian menunjukkan putaran motor asinkron bisa dikendalikan dengan mengubah frekuensi.

Oleh karena itu, perubahan frekuensi akan mempengaruhi perubahan kecepatan pada poros motor induksi asinkron. Selain itu besarnya torsi motor asinkron tetap konstan, dengan cara memberi input tegangan pada kumparan stator motor pada nilai konstan.[2].

Dalam penelitian "Analisis Penggunaan Energi Listrik dengan Menggunakan VSD", memaparkan bahwa perbandingan, mensuplay energi listrik pada motor menggunakan VSD, lebih rendah sebesar $0,149 \mathrm{kWh}$, dibanding tanpa menggunakan VSD penghematan energi listrik sebesar 31,10\% per bulan.[3].

Motor induksi a sinkron arus bolak-balik, sering digunakan pada mesin-mesin industri maju. Motor asinkron tiga phasa, beroperasi pada sistem jaringan distribusi tiga phasa, dan masih banyak ragam, kepentingan industri dengan kapasitas bervariasi besarnya, ditunjukkan pada Gambar 1.

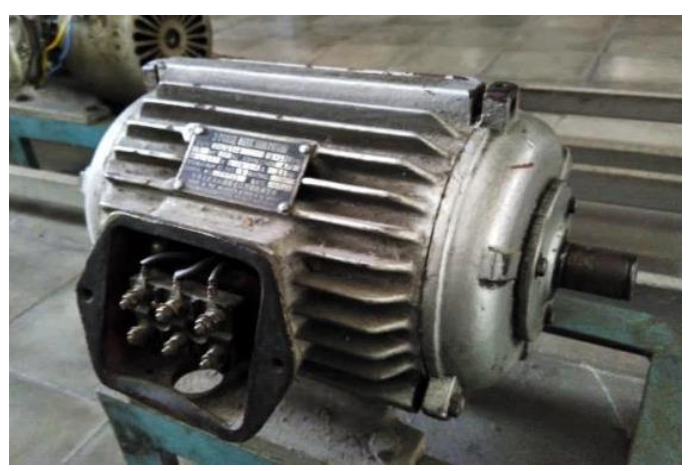

Gambar 1 Motor asinkron 3 phasa 2 HP [4]

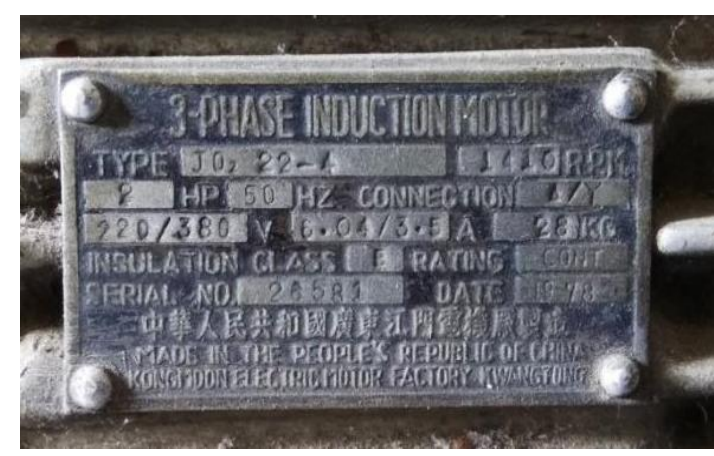

Gambar 2 Nameplate motor asinkron 3 phasa [4].

\section{Kelebihan:}

a. Konstruksi motor sederhana dan kokoh.

b. Harga murah dan handal.

c. Efisiensi kerjanya cukup tinggi, tidak terjadi rugi gesek, dan menpunyai power factor cukup baik

d. Estimasi biaya perawatan rendah.

e. Pengaturan starting motor yang sederhana.

Kekurangan:

a. Kecepatan tidak dapat divariasikan tanpa mengabaikan beberapa efisiensi. 
b. Kecepatan mengalami penurunan seiring penambahan beban.

c. Torsi starting rendah daripada jenis motor $\mathrm{dc}$ shunt.

\section{LANDASAN TEORI}

Terdapat beberapa prinsip-prinsip penting, pada motor asinkron 3 phasa, yaitu:

\subsection{Putaran motor induksi}

Kecepatan putar medan sinkron dapat dikalkulasi dengan menggunakan persamaan 1 yaitu:

dimana :

$$
n_{s}=\frac{120 \cdot f}{P}
$$

Ns = Kecepatan putaran medan stator (rpm),

$\mathrm{f} \quad=$ Frekuensi jala-jala $(\mathrm{Hz})$

$120=$ Konstanta,

$\mathrm{P}=$ Pasang kutub pada motor (pole)

Kuat medan magnet akan memotong motong batang konduktor pada rotor, akibat-nya timbul tegangan asinkron sebesar (E). Karena merupakan rangkaian tertutup dan menghasilkan arus (I). Adanya arus (I) menimbulkan gaya (F) dirotor. [5].

\subsection{Slip Motor Induksi}

Perbedaan antara kecepatan medan putar pada stator, dengan putaran rotor disebut slip dirumuskan pada persamaan 2 .

$$
S=\frac{n s-n r}{n s} \times 100 \%
$$

dimana:

$$
\begin{aligned}
& \mathrm{S}=\text { Slip } \\
& \mathrm{Ns}=\text { Putaran Sinkron } \\
& \mathrm{Nr}=\text { Putaran Rotor }
\end{aligned}
$$

\subsection{Torsi Motor Induksi}

Torsi adalah kemampuan daya gerak, untuk mensuplai beban mekanik. Sehingga (T) secara umum dapat dirumuskan pada persamaan 3 .

$$
T=\frac{P}{\omega r}
$$

dimana :

$\mathrm{T}=$ Torsi

$\mathrm{P}=$ Daya

$\omega r=$ kecepatan sudut angguler rotor
Hubungan torsi dengan perubahan frekuensi, perubahan beban ditunjukkan pada Gambar 3.

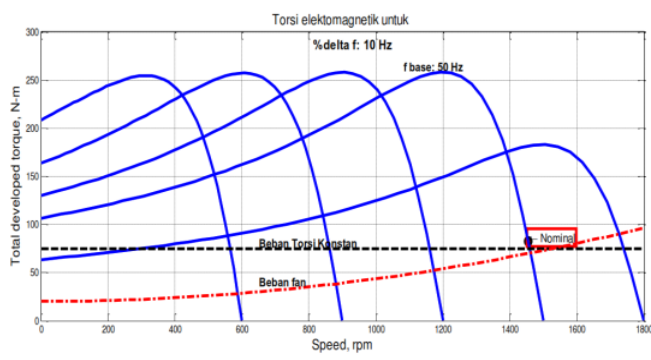

Gambar 3 Karakteristik pengaturan tegangan.

Pada Gambar 3 dapat dilihat sebuah grafik, menunjukkan pengaturan tegangan pada motor induksi terjadi karena:

a. Perubahan frekuensi, mempengaruhi perubahan kecepatan putaran rotor pada motor induksi.

b. Perubahan frekuensi nominal atau dibawah nominalnya, tetap torsi konstan. Jika frekuensi diatas nominalnya torsi akan turun.

\subsection{Variable Speed Drive (VSD)}

Penggunaan motor asinkron di industri semakin banyak, mengingat kesederhanaan konstruksi, dan kemudahan perawatannya.

Kelebihan motor asinkron dapat dikendalikan dengan perubahan frekuensi. Metode tersebut memungkinkan pengaturan kecepatan putarnya. Berkembangnya teknologi semikonduktor dewasa ini, mendorong berkembangnya peralatan pengatur kendali motor induksi asinkron, menggunakan inverter biasa disebut VSD. Karena metode pengendaliannya dilakukan, dengan mengatur tegangan dan frekuensi secara bersamaan. Devais semacam ini disebut Voltage Variable Frequency (VVF) atau Volt/ Hertz Inverter.

Metode ini bertujuan untuk mengendalikan, putaran poros motor induksi dan torsinya bisa dikendalikan secara bersamaan. Berkembangnya peralatan ini memberikan tambahan keuntungan, penggunaan motor induksi yaitu penggunaan motor menjadi lebih efisien, peningkatan fleksibilitas produksi dan peningkatan usia pemakaian pada kecepatan nominalnya.[6].

Jadi dengan mengatur perubahan frekuensi dan tegangan yang masuk ke motor, putaran motor akan berubah karena inverter disebut sebagai VSD. Kecepatan putaran medan stator, dapat di ditentukan dengan menggunakan persamaan 4.[2] 


$$
N_{S}=120 . f p
$$

dimana :

$$
\begin{array}{ll}
\mathrm{N}_{\mathrm{S}} & =\text { kecepatan putaran medan } \\
120 & =\text { konstanta } \\
\mathrm{f} & =\text { frekuensi }(\mathrm{Hz}) \\
\mathrm{p} & =\text { pasaang kutup motor (pole) }
\end{array}
$$

Setelah tegangan diubah menjadi tegangan searah, diperlukan perbaikan kualitas tegangannya, dengan menggunakan komponen kapasitor sebagai perata. Teknik PWM (PulseWidth Modulation) bisa membangkitkan amplitudo dan frekuensi keluaran. Teknik PWM memunculkan harmonisa pada jaringan, dan menghasilkan gelombang sinusoidal. Pengaruh harmonisa, dapat menimbulkan rugi-rugi daya pada motor dan akibatnya cepat panas.

Teknik PWM biasanya digunakanuntuk mengubah, tegangan searah menjadi bolak-balik (Inverter). Pada umumnya VSD diguna-kan untuk berikut ini:

1. Menyesuaikan kecepatan pengendali dengan keperluan kecepatan proses.

2. Menyesuaikan torque (kopel/torsi) pengendali dengan keperluan kopel proses.

3. Menghemat energi dan meningkatkan efisiensi.

Pada penelitian ini menggunakan VSD tipe ATV312HU15N4 diproduksi oleh Schneider Electric.

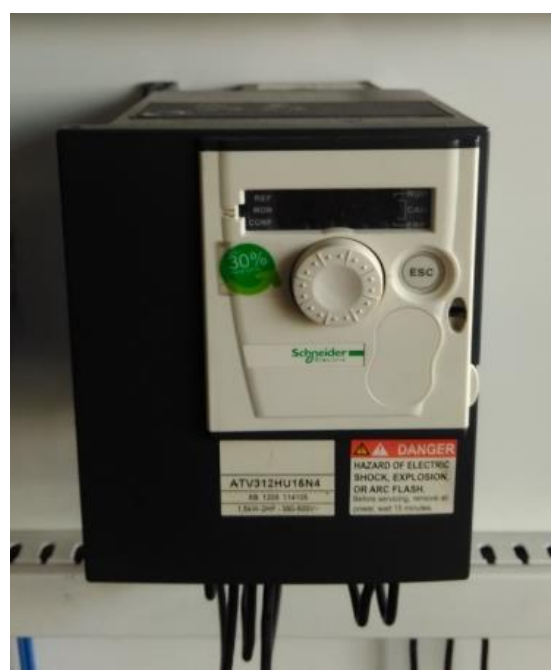

Gambar 4 Tipe VSD ATV312HU15N4 [6].

Penelitian ini menggunakan VSD tipe ATV312HU15N4, diproduksi oleh Schneider Electric. Schneider Electric adalah perusahaan Prancis, yang bekerja sama dengan Westing- house Systems sebuah grup yang bergerak di bidang kelistrikkan. Adapun kelebihan dari ATV312HU15N4 dengan input 3 fasa dengan output 3 fasa dengan spesifikasi $1,5 \mathrm{~kW}, 2 \mathrm{Hp}$, 380-500VAC, sehingga dapat mengendalikan motor 3 fasa dengan merubah frekuensi yang diinginkan serta dapat merubah arah putar motor induksi forward atau riverse. Berikut VSD yang digunakan ditunjukkan pada Gambar 4.[6].

\subsection{Operasi VSD ATV312HU15N4}

VSD digunakan untuk mempertahankan nilai tegangan keluaran ke frekuensi (V/F) dengan nilai rasio konstan pada semua kecepatan. Tegangan phasa (V), frekuensi $(\mathrm{F})$ dan fluks magnetik $(\phi)$ motor terkait dengan persamaan 5,6:(5) (6).

$$
\begin{aligned}
& V=4,444 f N \phi m \\
& V / f=4,444 N \phi m
\end{aligned}
$$

dimana :

$\mathrm{N}=$ jumlah lilitan stator berubah per fase. $\phi \mathrm{m}=$ fluks magnetik

Jika tegangan dikenakan pada frekuensi yang berkurang, maka fluks magnetik akan meningkat dan menjenuhkan daripada inti magnetic. Secara signifikan mendistorsi kerja motor, pada daerah saturasi magnetik dapat dihindari. $(\phi \mathrm{m})$ sesuai dengan perancangannya sebagaimana digunakan persamaan 6.[7].

Tegangan yang dilalukan ke stator harus dapat diatur, secara proporsional terhadap frekuensi. Dalam operasi kecepatan rendah, tegangan stator harus dinaikkan secara tepat. Jika motor diputar dengan frekuensi yang lebih tinggi daripada frekuensi dasarnya, mengakibatkan pengurangan terhadap torsi yang dihasilkan, sehingga menyebabkan arus magnetisasi akan berkurang dan mengakibatkan melemahnya medan magnet.[8].

\subsection{Magnetic Contactor (MC)}

Kontaktor magnet (MC) suatu perangkat komponen listrik bekerjanya, dipengaruhi prinsip induksi elektromagnetik. Kontaktor magnet didalanya terdapat kumparan kawat email dari tembaga, jika diberikan arus listrik akan menarik inti besinya, kontaknya akan berhubungan satu sama lainnya. Kontak NO (Normally Open) dalam keadaan normal akan membuka dan NC (Normally Close) keadaan akan menutup.

Kontak-kontak pada MC terdiri, dari 
kontak primer dan kontak skundair. Kontak primer digunakan untuk line utama sedangkan kontak skundair digunakan untuk rangkaian pengendali. Didalam suatu kontaktor elektromagnetik terdapat lilitan premer, yang yang menggerakkan inti besi.

Kumparan hubung skundaer berfungsi sebagai pembatas gerakan dari kedua inti besi agar tidak saling melekat. Apabila lilitan primer dialiri arus listrik, akan timbul medan magnet pada inti besi yang menarik inti besi dari lilitan hubung singkat. Hal ini akan mengakibatkan kontak primer dan skundair, akan bergerak dari posisi normal dimana kontak NO akan tertutup untuk kontak NC tertutup.

Selama kumparan primer kontaktor masih dialiri arus listrik, maka kontak-kontak-nya akan tetap pada posisi bekerja. Apabila pada kumparan primer kontaktor diberi tegangan yang terlalu tinggi, maka akan menyebabkan berkurangnya umur pada kumparan kontaktor. Tetapi jika tegangan yang diberikan terlalu rendah, akan menggurangi kemampuan tekanan pada kontak-kontak MC.

Hal ini menimbulkan bunga api pada permukaannya serta dapat merusak kontakkontaknya. Batas toleransi tegangan pada kumparan kontaktor berkisar 85\%-110\% dari tegangan kerja kontaktor. Kontaktor yang digunakan dalam penelitian, kontaktor produksi Schneider Electric dengan tipe LC1D12, 3 pole, 12 Ampere 230 volt $\mathrm{AC}, 5,5 \mathrm{~kW}$.

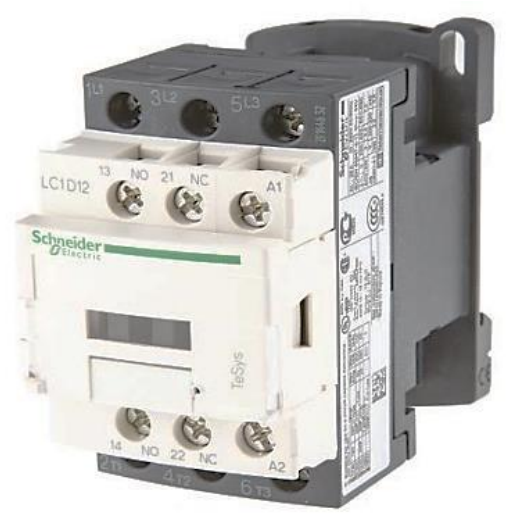

Gambar 5 Magnetic Contactor Schneider Electric LC1D12 [6].

\subsection{Prinsip kerja kontaktor}

Kerja kontaktor berdasarkan input tegangan 220VAC, sesuai karakter kumparan didalamnya. Kemudian tegangan menggerakan inti besi didalam coil, kontaktor akan bekerja ketika ada magnet didalamnya untuk menarik kontak pada line R,S,T. Sedangkan kontak skundair dari kontaktor, saat kondisi NO berubah menjadi NC, dan untuk membuka (opening) kontakor memerlukan waktu 4-19ms dan menutup (close) 12-22ms.

Kemampuan kerja kontaktor untuk daya besar, akan menimbulkan bunyi yang keras. Ketika Arus yang mengaliri lilitan tersebut dimatikan atau off, maka magnet pada lilitan didalamnya akan hilang dan tidak menarik kontak dari kontaktor.

\section{METODELOGI PENELITIAN}

Prinsip Kerja VSD, tegangan output dari VSD, yaitu suatu tegangan yang dapat diatur dan akan mempengaruhi besaran nilai frekuensinya. Berikut ini iperlihatkan prinsip kerja VSD dapat dilihat pada Gambar 6, merupakan diagram cara kerja VSD yang dapat dijabarkan sebagai berikut:

a. Input tegangan jala-jala 220/380 volt, frekuensi $50 \mathrm{~Hz}$ sebagai tegangan arus bolak-balik, yang konstan melalui diode penyearah. Untuk dijadikan dari AC dijadikan DC.

b. Untuk mendapatkan tegangan searah yang rata, maka diperlukan komponen tambahan berupa kapasitor dan induktor.

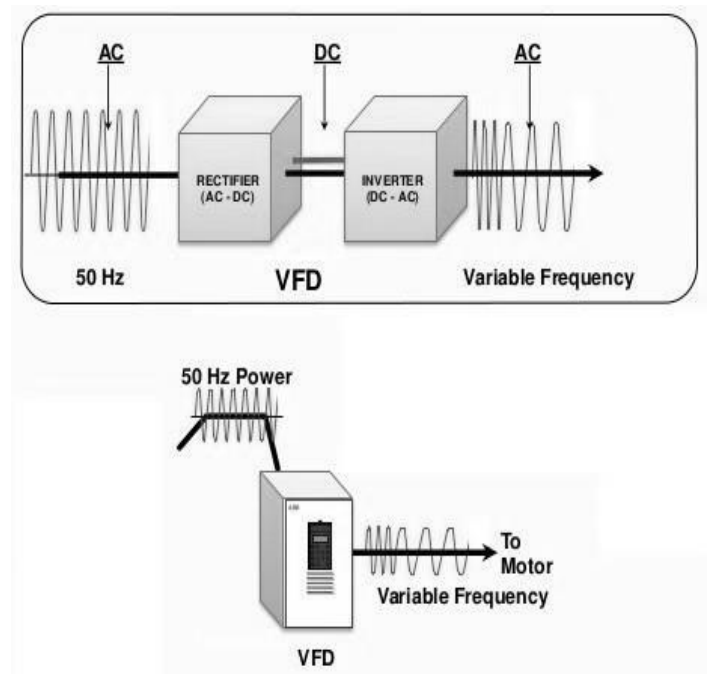

Gambar 6 . Diagram prinsip kerja Variable Speed Drive. (Sumber:http://tiny.cc/fjixfz)

Perancangan Alat, pertama-tama dibuat suatu gambar rancangan, dan rangkaian kerja untuk pengendalian kecepatan putar poros motor asinkron, yang berfungsi untuk mempermudah dalam pengintregrasian pemasangan beberapa bahan komponen-komponen yang digunakan.

Agar rancangan dibuat dapat beroperasi 
secara maksimal, maka sebelumnya dapat mengkaji terlebih dahulu bahan-bahan yang dipasang dan karakteristik dari komponen yang digunakan.

Rangkaian Kontrol Panel, pada Gambar 7 memperlihatkan diagram pengawatan VSD, hal ini menunjukkan secara real pengawatan pada satu rangkian pengendalian motor asin-kron dengan VSD.

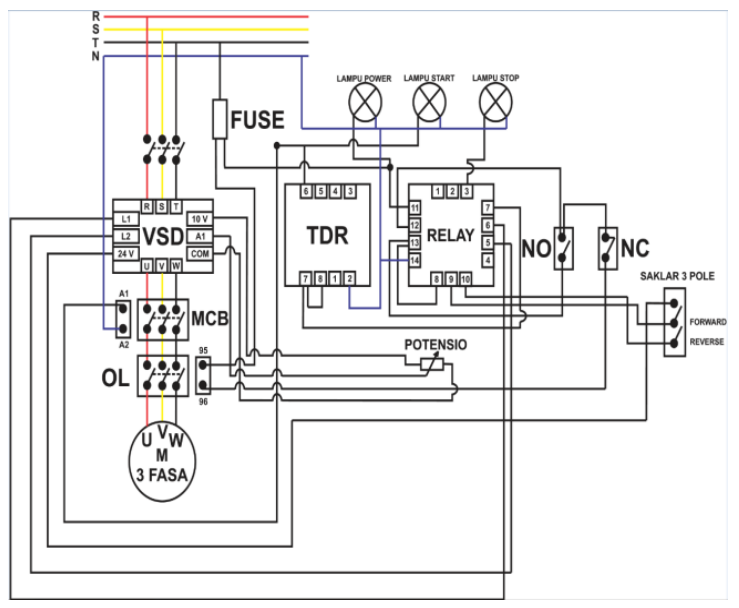

Gambar 7 Wiring diagram VSD

Apabila memungkinkan, khusunya pada panel kendali, digram ini haruslah menunjukkan letak komponen yang sesungguhnya. Rangkaian pengawatan kelistrikkan dibuat, dari mulai input sampai output dan diberi beban dalam rangkaian, sehingga sistem kendali putran mesin dapat ditetapkan. Komponen sudah terpasang maka dilanjutkan dengan pengawatan atau wiring dengan melihat gambar diagram pengawatan pada gambar 7. Sedang-kan kabel yang digunakan pada rangkaian kendali menggunakan kawat nya $1.5 \mathrm{~mm}$.

\section{HASIL PENELITIAN}

Penelitian ini telah dilakukan pengujian terhadap pengendalian motor asinkron tiga phasa menggunakan Variable Speed Drive tipe ATV312HU15N4, maka data yang sudah diperoleh adalah sebagai berikut:

\subsection{Analisis VSD pada kondisi motor tak berbeban.}

Hasil yang dilakukan di Laboratorium pengukuran tegangan dan arus pada frekuensi $10-50 \mathrm{~Hz}$, untuk motor tak berbeban, sebagaimana di tunjukkan pada table 1

Tabel 1. Data hasil implementasi tegangan dan arus pada motor tak berbeban

\begin{tabular}{|c|c|c|c|c|c|c|c|c|}
\hline \multirow{2}{*}{$\begin{array}{c}\text { Frekuensi } \\
\text { (Hz) }\end{array}$} & \multicolumn{4}{|c|}{ Tegangan (V) } & \multicolumn{4}{c|}{ Arus (I) } \\
\cline { 2 - 9 } & $\mathbf{R}$ & $\mathbf{S}$ & $\mathbf{T}$ & Rata-rata & R & S & T & Rata-rata \\
\hline $\mathbf{1 0}$ & 315.7 & 292.8 & 307.73 & 305,11 & 9.78 & 6.28 & 7.44 & 7.83 \\
\hline $\mathbf{2 0}$ & 331.7 & 323.3 & 333.26 & 329.42 & 8.84 & 6.25 & 7.41 & 7.48 \\
\hline $\mathbf{3 0}$ & 333.8 & 330.2 & 340.2 & 333.58 & 8.46 & 7.13 & 6.34 & 7.25 \\
\hline $\mathbf{4 0}$ & 413.6 & 402.7 & 412.28 & 396.98 & 6.79 & 4.66 & 5.88 & 5.7 \\
\hline $\mathbf{5 0}$ & 467.72 & 456.26 & 464.26 & 465.3 & 7.38 & 4.98 & 5.92 & 6.05 \\
\hline
\end{tabular}

Tabel 2. Data hasil implementasi tegangan dan arus pada motor berbeban

\begin{tabular}{|c|c|c|c|c|c|c|c|c|}
\hline \multirow{2}{*}{$\begin{array}{c}\text { Frekuensi } \\
(\mathbf{H z})\end{array}$} & \multicolumn{4}{|c|}{ Tegangan (Volt) } & \multicolumn{4}{c|}{ Arus (ampere) } \\
\cline { 2 - 9 } & $\mathbf{R}$ & $\mathbf{S}$ & $\mathbf{T}$ & Rata-rata & $\mathbf{R}$ & $\mathbf{S}$ & $\mathbf{T}$ & Rata-rata \\
\hline $\mathbf{1 0}$ & 474.68 & 316.63 & 342.68 & 377.97 & 7.46 & 4.79 & 5.48 & 5.91 \\
\hline $\mathbf{2 0}$ & 435.26 & 294.79 & 323.89 & 351.31 & 7.73 & 4.69 & 5.1 & 5.84 \\
\hline $\mathbf{3 0}$ & 416 & 378.38 & 388.39 & 394.25 & 7.31 & 4.6 & 5.45 & 5.78 \\
\hline $\mathbf{4 0}$ & 359 & 281.55 & 349.69 & 330.08 & 9.81 & 6.42 & 6.72 & 7.65 \\
\hline $\mathbf{5 0}$ & 337.07 & 286.86 & 348.48 & 324.13 & 9.78 & 6.4 & 7.1 & 7.76 \\
\hline
\end{tabular}


Analisis operasional kendali untuk VSD dengan tipe ATV312HU15N4, diarahkan untuk mengendalikan motor asinkron 3 phasa, sebagai ouputnya ditambah dikople dengan beban motor asinkron 3 phasa, pada frekuensi $10 \mathrm{~Hz}$ sampai $50 \mathrm{~Hz}$. Dalam analisis peng-ambilan data masing masing setiap tahap frekuensi dilakukan pengukuran 10 kali percobaan menggunakan alat ukur power quality analyzer.

Tabel 3. Data hasil implementasi daya, $\cos \varphi$, rpm pada motor tak berbeban

\begin{tabular}{|c|c|c|c|}
\hline Frek.(Hz) & Daya $(\mathbf{k W})$ & $\cos \boldsymbol{\varphi}$ & rpm \\
\hline $\mathbf{1 0}$ & 1.68 & 0.5017 & 313 \\
\hline $\mathbf{2 0}$ & 1.77 & 0.4788 & 624 \\
\hline $\mathbf{3 0}$ & 1.75 & 0.4668 & 914 \\
\hline $\mathbf{4 0}$ & 1.67 & 0.4238 & 1214 \\
\hline $\mathbf{5 0}$ & 1.91 & 0.4089 & 1509 \\
\hline
\end{tabular}

\subsection{Analisis VSD pada Motor Berbeban}

Data hasil implementasi tegangan dan arus pada motor berbeban, sebagaimana di tunjukkan pada table 4 .

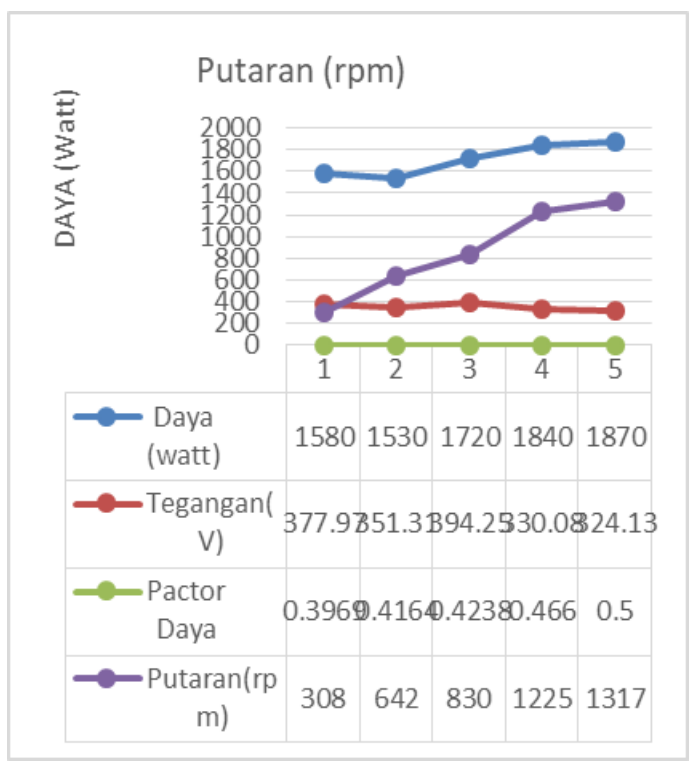

Gambar 8 Hasil Pengukuran Tegangan Motor Berbeban

Hasil analisis penelitian yang dilaksanakan, didapat beberapa hasil perhitungan yang mengacu pada hasil pengukuran dari data tabel 1 dan tabel 2, diantaranya adalah perhitungan torsi (Nm). Hasil perhitungan tersebut untuk menentukan tenaga gerak pada motor asinkron 3 phasa.
Tabel 4. Data hasil implementasi daya, $\cos \varphi$, rpm pada motor berbeban

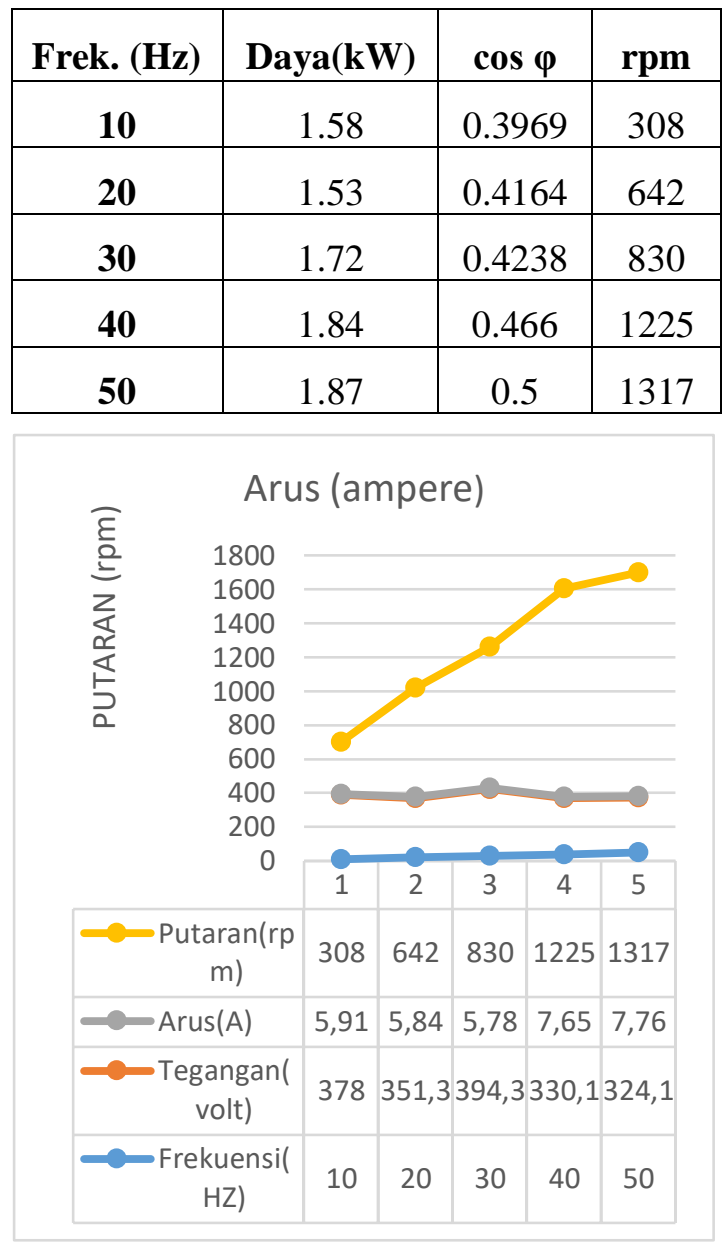

Gambar 9 Hasil Pengukuran Arus Motor Berbeban

Sedangkan tabel 3 dan table 4, merupakan hasil pengukuran untuk menentukan sebuah gambar grafik 8 dan 9. Hal ini untuk melihat seimbang antara, input sumber tegangan pada VSD untuk menjalankan motor asinkron 3 phasa tanpa beban.

\section{SIMPULAN}

Hasil analisis pada peralatan yang sudah dirancang, maka diperoleh beberapa kesimpulan, yaitu :

1. Hasil pengujian dengan powerquality analyzer nilai tertinggi difrekuensi $50 \mathrm{~Hz}$, pada motor tak berbeban diperoleh tegangan (V) sebesar R : 467,72 V, S : 456,26 V, dan $\mathrm{T}$; 464,26. Kemudian nilai tertinggi pada arus (A) sebesar R : 7,38 A, S : 4,98, dan T: 5,92 . Kemudian nilai tertinggi daya dalam $(\mathrm{kW})$ motor asinkron sebesar $1,9 \mathrm{~kW}$.

2. Sedangkan di frekuensi $50 \mathrm{~Hz}$ pada motor 
berbeban, diperoleh tegangan $(\mathrm{V})$ sebesar $\mathrm{R}$ : $337,07 \mathrm{~V}, \mathrm{~S}: 286,86 \mathrm{~V}$, dan $\mathrm{T}: 348,48 \mathrm{~V}$. Kemudian nilai tertinggi pada aus (A) sebesar R : 9,78 A, S : 6,4 A, dan T : 7,1 A. Kemudian nilai tertinggi daya dalam $(\mathrm{kW})$ motor asinkron sebesar $1,87 \mathrm{~kW}$.

3. Hasil pengukuran yang diperoleh dari, kecepatan motor tiga phasa frekuensi $50 \mathrm{~Hz}$, kecepatan pada motor tak berbeban sebesar 1493,24 rpm. Kemudian kecepatan motor berbeban sebesar $1317 \mathrm{rpm}$.

\section{KEPUSTAKAAN}

[1] Pranata.Y, Teguh Arfianto.T, Taryana.N, Analisis Unjuk Kerja Motor Induksi 3 Fasa Menggunakan Inverter 3 Fasa. TELKA, ISSN (e): 2540-9123, Vol.4, No.2, November 2018, pp. 91 102

[2]. Deni Nurul Huda. 2012. Pengujian Untuk Kerja VSD, VF-S9 Dengan Beban Motor Induksi 3 Fasa $1 \mathrm{Hp}$. Politeknik Bandung.

[3] Atmam, dkk. 2018. Analisis Penggunaan Motor Induksi Tiga Phasa Menggunakan VSD, Universitaas Lancang Kuning. Pekanbaru

[4]. M. Suyanto, 2015., Buku Panduan praktikum Instalasi Listrik Arus Kuat IST AKPRIND Jogjakarta.

[5]. Hartono.BP, Nurcahyo.E, 2017. Analisis Hemat Energi Pada Inverter Sebagai Pengatur Kecepatan Motor Induksi 3 Fasa, Jurnal Elektrika. 1(1), , pp. 9-16.

[6]. Schneider Electric. Profibus DP communication manual VSD ATV312HU15N4

[7]. Zulkarnaini. 2013. Pengaruh Harmonik Akibat Penggunaan Variable Speed Drive Terhadap Piranti Bridge Crane PLTU Teluk Sirih (2X112MW). Jurnal Teknik Elektro. ITP

[8]. Nugroho, EA, 2018. Implementasi Sistem Kendali Variable Speed Drive Pada inverter 3 Fasa Jurnal SIMETRIS, Vol. 9 No. ISSN: 2252-4983. 